\title{
Mechanical characterisation of ABS/MWCNT composites under static and dynamic loading conditions
}

\author{
Prashant Jindal $^{1 *}$, Jeevan Jyoti² and Navin Kumar ${ }^{3}$ \\ ${ }^{1}$ University Institute of Engineering \& Technology, Panjab University, \\ Chandigarh-160014, INDIA \\ *Email: jindalp@pu.ac.in \\ Phone: +919878881230 \\ ${ }^{2}$ Physics and Engineering of Carbon, CSIR-National Physical Laboratory, \\ New Delhi-110012, INDIA \\ ${ }^{3}$ Indian Institute of Technology, Ropar-140001, Punjab, INDIA
}

\begin{abstract}
In this paper, our aim is to evaluate the static and dynamic mechanical properties of Acrylonitrile-Butadiene-Styrene (ABS) terpolymer and its composites with small compositions of Multi-Walled Carbon Nanotubes (MWCNTs). Composites of ABS/MWCNT were fabricated with various MWCNT compositions $(3,5,10$ wt \%) in ABS using twin screw extrusion method. These were then characterised under quasi-static loading to obtain hardness and elastic modulus using nano-indentation technique. It was observed that hardness and modulus for 10wt \% MWCNT composition in ABS/MWCNT composites were enhanced by $49 \%$ and $61 \%$ respectively, in comparison to pure ABS specimen. The visco-elastic nature of ABS/MWCNT composites was also investigated at nano scale using Dynamic Mechanical Analysis (DMA). In the dynamic mode, it was observed that modulus of $10 \mathrm{wt} \%$ ABS/MWCNT composite was higher, by nearly $58 \%$ to $75 \%$, for a loading frequency range upto $200 \mathrm{~Hz}$, in comparison to that of pure ABS. Therefore, we could observe, that mechanical properties of ABS composites were enhanced significantly by comprising them with minor compositions of MWCNTs(upto $10 \mathrm{wt} \%$ ), hence improving the prospects where light weight components made of ABS material need to be subjected to static and dynamic loading, such as automotive machine and body parts.
\end{abstract}

Keywords: Nano-composites; carbon nanotubes; Hardness; Twin Extrusion

\section{INTRODUCTION}

Among the large variety of polymers, Acrylonitrile-Butadiene-Styrene (ABS) terpolymer has attracted a lot of attention due its high impact resistance, dimensional stability, good surface texture and toughness. Due to these attractive mechanical properties, ABS is widely used in golf club heads, automotive bumper bars and protective headgear where impact and shock resistance properties are most important. The already existing ABS can be further modified by adding filler materials and forming composites, which can further enhance its mechanical properties without adding significantly to its overall weight. Previous studies showed that incorporating short fibre into neat ABS to balance the toughness and stiffness resulted in an improvement of tensile strength and modulus values, but this increase was low. ABS was reinforced with HNO3-treated short carbon 
fibres (HCFs). The effects of HCF concentration on the tensile properties of the composites were examined [1]. Increasing the HCF concentration in the ABS matrix from 10 wt. $\%$ to 30 wt. \% resulted in improved tensile strength and tensile modulus consistently by about $10 \%$. To obtain a strong interaction at the interface, polyamide- 6 (PA6) at varying concentrations was introduced into the ABS/10 wt. \% HCF composite. The incorporation and increasing amount of PA6 in the composites increased tensile properties of the ABS/PA6/HCF systems due to the improved adhesion at the interface. The presence of PA6 also enhanced the tensile strength and modulus by nearly $10 \%$. However, a further increase in the amount of PA6 in HCF-reinforced composites over the amount of PA6 required had no significant effect on tensile properties of the ABC/HCF composites. Spitalsky et al. [2] have observed that the addition of Carbon Nanotubes(CNTs) in ABS enhances the tensile strength and Young's modulus by $31 \%$ and $93 \%$ respectively. Addition of only $5 \mathrm{wt} \%$ pristine SWCNTs was sufficient for this enhancement. CNT sidewalls nucleate the crystallisation of the polymer, thus leading to stiffer composite. Meincke et al. [3] used ABS in conjunction with PA6 and CNTs. To investigate the effect of the nanotubes as selective filler for the polyamide- 6 phase on the mechanical properties of the blend, tensile tests and Izod impact tests were conducted. The composites showed an increase in the Young's modulus with increasing filler content. This increase was linear in the observed composition range. The unfilled blend showed a Young's modulus of $1970 \mathrm{MPa}$, while the blend with the highest loading of nanotubes (7 wt. \%) showed a modulus of $2510 \mathrm{MPa}$ which corresponds to an increase of $27 \%$. It was suggested that the presence of CNTs and PA6 caused a double percolation effect which raised the stiffness of blends. This rise in stiffness has been suggested reason for increase of Young's Modulus. The elongation at break indicated a decrease with increasing filler content in CNTs-filled blends. However, the Izod test results indicated that the notched unfilled blends had impact strength of approximately $70 \mathrm{~kJ} / \mathrm{m}^{2}$. This value indicated high toughness. With increase in the filler content the notched impact strength decreased substantially in the CNTs -filled composites. It reached almost half the impact strength of unfilled blend for a composition of $12 \%$ CNTs. Difallah et al. [4] investigated the mechanical properties of ABS composites using tensile test. It was observed that the mechanical properties significantly decreased with the increase of graphite particles amount. The failure strain and the elastic modulus were significantly higher for the unfilled polymer, and then decreased sharply with the addition of graphite beyond 2.5 $\mathrm{wt} \%$. The failure stress decreased gradually with the increase in graphite content from $0 \%$ to $2.5 \%$. The failure strain also fell from $11 \%$ to $4.2 \%$ and the elastic modulus reduced from $2050 \mathrm{MPa}$ to about $1250 \mathrm{MPa}$. In addition, the failure stress decreased from $35 \mathrm{MPa}$ to $17.5 \mathrm{MPa}$ as the weight fraction of graphite increased from $0 \%$ to $7.5 \%$. These tendencies implied that the addition of graphite had a significant effect on the alteration of the mechanical properties of ABS. The reasons for this were mainly attributed to the weak interface interaction and the lack of chemical bonding between $A B S$ and the graphite powder.

In other polymer composites, like polymer poly(methyl methacrylate) (PMMA) [5], it was reported that the presence of MWCNTs did not improve any static mechanical property. Even with change in compositions from $1 \%$ to 5\% of MWCNTs the elastic modulus and hardness remained almost same to that pure PMMA. However, if the MWCNTs were coated with silica, the composite showed remarkable results upon nanoindentation. With only 4\% MWCNT-Silica in PMMA, the hardness measured about two times to that of pure PMMA and modulus measured about three times to that of pure PMMA. Polypropylene (PP) when incorporated with CNTs and silica showed 
enhancement [6] in mechanical properties by nearly 35\%. When similar nano-indentation tests were conducted on acid modified Multi-Walled Carbon Nanotubes (a-MWCNT) reinforced Polyurethane (PU) composites, very interesting observations [7] were made. Hardness for $10 \mathrm{wt} \%$ a-MWCNT/PU specimen improved by nearly $271 \%$ in comparison to pure PU, while the elastic modulus improved by nearly three times in comparison to pure PU. Jindal et al. [8] characterised composites of MWCNT fillers with polycarbonate as base material and observed that there is a consistent rise by more than $50 \%$ in both elastic modulus and hardness with increase in MWCNT composition(up to 10wt\%). Mechanical characterisation using simulation and modelling [9] techniques have also indicated enhancement in mechanical properties at nano level for MWCNT based polymer composite materials. Even properties related to thermal conductivity and viscosity are enhanced with the presence of MWCNTs in nano-fluids [10].

On the basis of the available experimental studies, we observed that in most cases, using MWCNT in its untreated or as-synthesised form is not sufficient in enhancing mechanical properties of MWCNTs/polymer composites. Treatment or functionalisation of MWCNTs or an additional initiator is required in the composite specimen which results in better interaction and dispersion of MWCNTs with polymer base matrix. Also, it has been observed that there is lack of consistency in the available literature regarding the content of MWCNTs required for enhancing the mechanical strength of polymer composites. Different types of techniques like tensile testing, dynamic measurement analysis etc. have been adopted by researchers for evaluation of mechanical properties. Therefore, keeping the above mentioned factors in mind, in our present study we investigate changes in the dynamic and static mechanical properties (elastic modulus and hardness) for various compositions of as-synthesised/untreated MWCNTs in ABS by employing nano-indentation techniques without any additional component or surface modification during the composite fabrication procedure.

\section{EXPERIMENTAL SET UP}

\section{Sample Preparation}

MWCNTs were used as reinforcing material in the ABS base matrix to form composites with varying MWCNT compositions based on literature studies [11, 12] wherein major contribution of MWCNTs in polymers takes place below $10 \mathrm{wt} \%$. For minor ( $2 \mathrm{wt} \%$ to $5 \mathrm{wt} \%$ ) compositions of carbon fillers [13], significant enhancement in mechanical properties of composites have been reported. MWCNTs were synthesised by catalytic chemical vapour deposition technique in which toluene (99\% purity) was thermally decomposed in an $18 \mathrm{~cm}$ long constant heating zone of quartz tube in presence of ferrocene (purity 99\%). This solution (0.077 gm ferrocene in $1 \mathrm{ml}$ toluene) was fed into heated quartz tube at a feeding rate of $10 \mathrm{ml} / \mathrm{h}$ in an inert atmosphere [14].

MWCNTs/ABS composites were prepared by the melt mixing on the co-rotating twin screw extruder (HAAKE MiniLab II Micro Compounder) followed by micro injection moulding. The twin screw extruder with back flow channel was used to disperse CNTs uniformly in the polymer. The temperature of the compounder $\left(265^{\circ} \mathrm{C}\right)$ and mixing time ( $3 \mathrm{~min}$.) was optimised for the preparation of composites. Rotation speed of screw was set to $100 \mathrm{rpm}$. Prior to incorporation of MWCNTs into the ABS matrix, polymer was dried in the vacuum oven at $100^{\circ} \mathrm{C}$ for $24 \mathrm{~h}$ to remove the moisture trapped in polymer beads. Micro injection moulding was connected to a mould of size $70 \mathrm{~mm}$ x 12.7 $\mathrm{mm} \times 3.2 \mathrm{~mm}$ (Figure-1). A series of MWCNTs/ABS composites with varied amounts of MWCNTs $(3,5,10 \mathrm{wt} \%)$ were prepared [15]. 


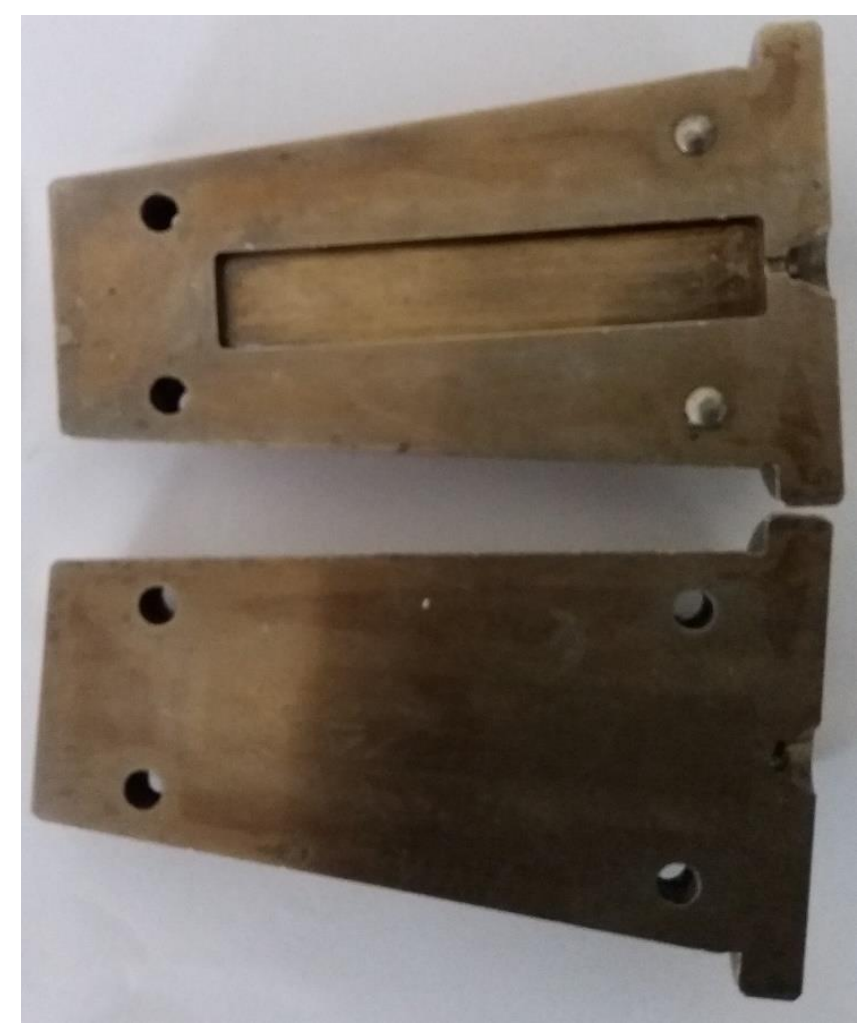

Figure 1. Mould for the ABS/MWCNT specimen.

Figure 2 represents the SEM image of $10 \mathrm{wt} \%$ ABS/MWCNT composite. MWCNTs are reasonable dispersed throughout the ABS specimen. Figure 3 shows the Raman spectra of the same composite. This Figure indicates the signature $D(1316 / \mathrm{cm})$ and $\mathrm{G}(1580 / \mathrm{cm})$ peaks, validate presence of MWCNTs in ABS/MWCNT composite specimen.

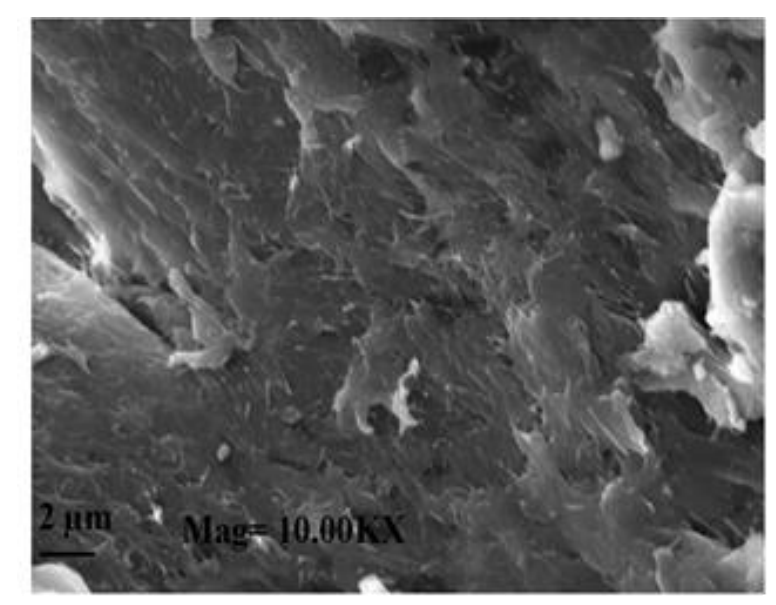

Figure 2. 10wt\% MWCNT uniform dispersion in ABS/MWCNT composite for an SEM image of scale $2 \mu \mathrm{m}$. 


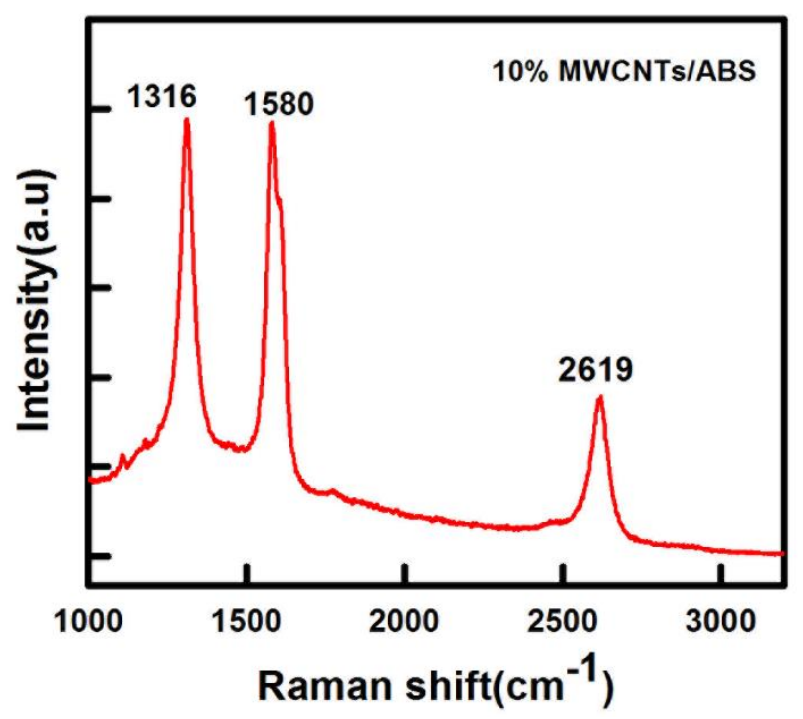

Figure 3. Raman spectra indicating the signature $D(1316 / \mathrm{cm})$ and $G(1580 / \mathrm{cm})$ peaks for the presence of MWCNTs in ABS/MWCNT composite.

\section{Mechanical Characterisation}

Nano-indentation tests [16] were performed at seven different points on each of the twenty samples of different compositions, thereby forming an ' $\mathrm{H}$ pattern' of indents using Hysitron T1 950 TriboIndentor equipped with a Berkovich tip. Overall observations were obtained at by five such $\mathrm{H}$ patterns all over the surface for each specimen. There were total 35 indentation points on each sample. Calibration of the tip was performed by using standard fused quartz and polycarbonate sample. A three sided pyramidal tip (Berkovich) with an included angle of 142.30 and tip radius of $150 \mathrm{~nm}$ was used. Region for indentation was identified using an in situ optical microscope integrated into the nanoindentation system by forming an ' $\mathrm{H}$ pattern' of indents. For area function calibration, a series of indents with different contact depths were performed on the standard sample of known elastic modulus and accordingly contact area was calculated. A plot of the calculated area as a function of contact depth was created and fitted. The hardness and modulus were compared using Oliver and Pharr [17] method.

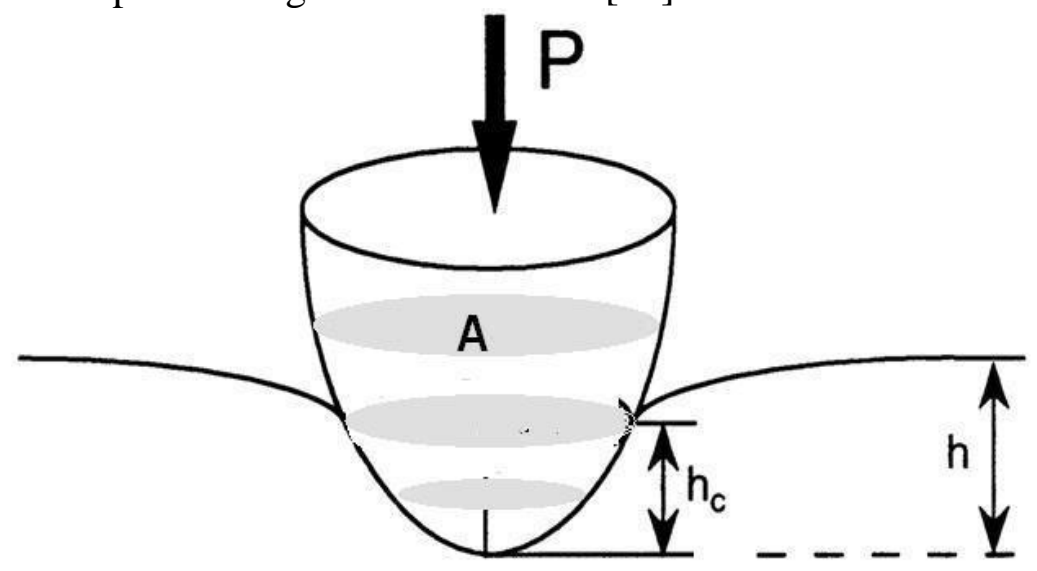

Figure 4. General representation of an indenter under static load pressing into a specimen surface [18]. 
Figure 4, indicates the indenter position during the pressing process inside the specimen. The projected contact area of the hardness impression, A, is estimated by evaluating an empirically determined indenter shape function at the contact depth, $h_{c}$ by using $\mathrm{A}=\mathrm{f}\left(h_{c}\right)$. Shape function, $\mathrm{f}(\mathrm{d})$ is used to relate the cross-sectional area of the indenter with its distance(d) from its tip. For a geometrically perfect Berkovich indenter, the shape function is given by $f(d)=24.56 \mathrm{~d}^{2}$, but for real Berkovich indenters, $f(d)$ is considerably more complex due to tip rounding.

Governing equations to find out hardness and modulus are given below

Applied load is expressed as follows:

$$
P=B\left(h-h_{f}\right)^{m}
$$

where $P$ is the applied load and $h$ is the depth of penetration, $h_{f}$ is the final depth of penetration. $B$ and $m$ are empirically determined fitting parameters.

Stiffness is defined as follows:

$$
S={\frac{d P}{d h_{h=h_{\max }}}}
$$

where the derivative is evaluated at $h_{\max }$.

Using equation (1), this becomes

$$
S=m B\left(h_{\max }-h_{f}\right)^{m-1}
$$

Contact depth is another parameter which is related to maximum depth

$$
h_{c}=h_{\max }-0.75 \times \frac{P_{\max }}{\left(\frac{d P}{d h}\right)}
$$

where $h_{c}$ is given as contact depth and $P_{\max }$ is given as maximum applied load.

Reduced Elastic Modulus:

When the stiffness is normalised by considering contact area, we define reduced elastic modulus as

$$
E_{r}=\frac{\sqrt{\pi}}{2 \sqrt{A\left(h_{c}\right)}} \times \frac{d P}{d h} \times \frac{1}{\beta}
$$

where $E_{r}$ is given as reduced modulus, $A\left(h_{c}\right)$ is given as contact area, $P$ is the applied load and $\beta$ is a constant that depends on geometry of indenter. For Berkovich $\beta$ is taken as 1.034 .

Hardness is defined as follows:

$$
H=\frac{P_{\max }}{A\left(h_{c}\right)}
$$

Finally, the measured elastic modulus has to be corrected for by considering the characteristics of the indenter and specimen on the account that both indenter and specimen undergo elastic deformation. 
Reduced modulus can also be calculated by:

$$
\frac{1}{E_{r}}=\frac{\left(1-v_{i}^{2}\right)}{E_{i}}+\frac{\left(1-v_{S}^{2}\right)}{E_{S}}
$$

where $E_{i}$ is the elastic modulus of the indenter and $v_{i}$ is the Poisson's ratio of the indenter while $E_{s}$ is the elastic modulus of the specimen and $v_{s}$ is the Poisson's ratio of the specimen.

Based on these equations direct results for hardness and elastic modulus are obtained after completion of one complete cycle of loading and unloading process during nano-indentation. Same specimens were used to evaluate storage modulus when loaded under different frequencies referred as Dynamic Mechanical Analysis (DMA). The results of these specimens were then compared with the indentation results of pure ABS samples to examine the effect of composition of MWCNTs on hardness, elastic modulus and storage modulus.

The mechanical properties of the samples were obtained by applying indent of known force and measuring the corresponding penetration depth. Figure-5 represents the load displacement curve. It represents the loading and unloading cycles for different compositions during the quasi static indentation process under a maximum constant load of $5000 \mu \mathrm{N}$. The final indentation depth indicates the extent to which the indenter was able to pierce inside the specimen surface. 10wt\% ABS/MWCNT composition showed minimum final indented depth of nearly $510 \mathrm{~nm}$ while for the pure ABS it was nearly 600 $\mathrm{nm}$. This shows that $10 \mathrm{wt} \%$ ABS/MWCNT composition was the hardest to indent in comparison to other compositions.

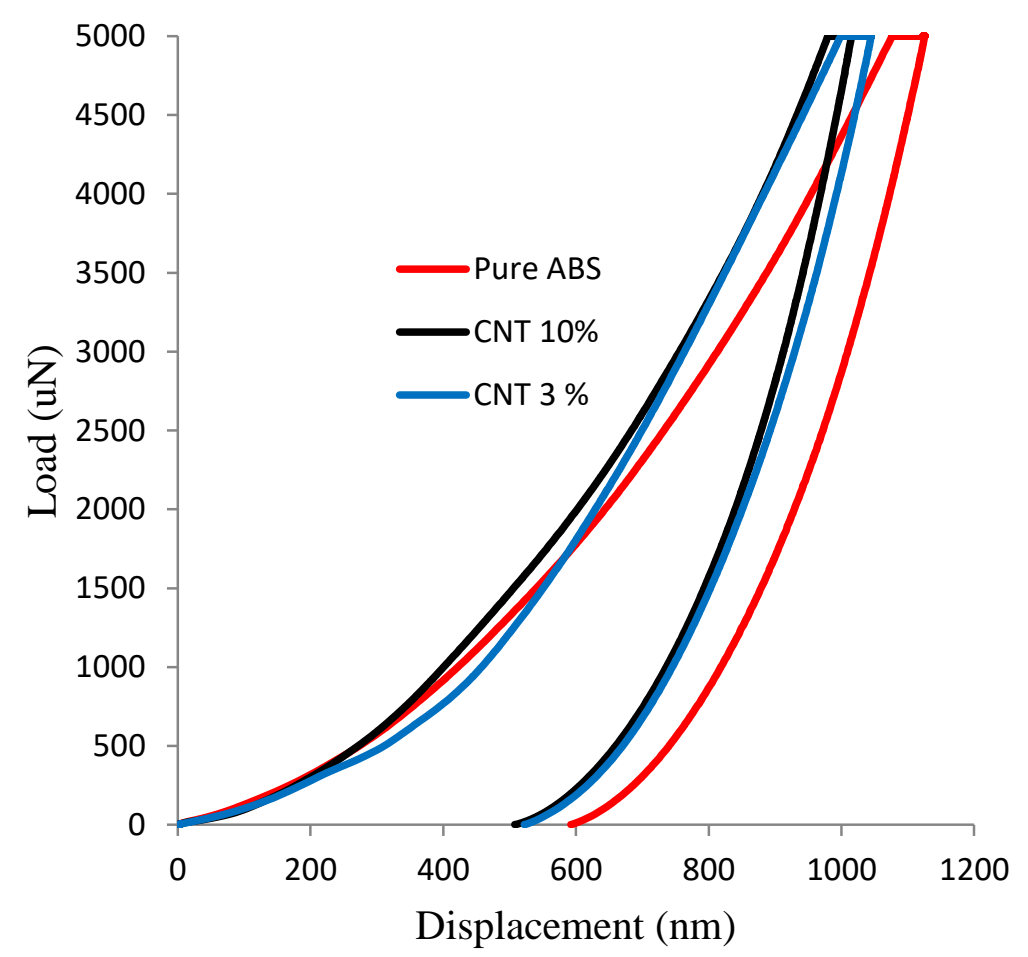

Figure 5. Load-displacement curves for various compositions under applied load of $5000 \mu \mathrm{N}$. 


\section{RESULTS AND DISCUSSION}

ABS/MWCNT composites with different MWCNT compositions were investigated for evaluating various mechanical properties. ABS/MWCNT composites being visco-elastic by nature, experience a change in their mechanical properties under different dynamic loading conditions. Both static and dynamic mechanical properties were experimentally investigated for various compositions of MWCNTs in the ABS/MWCNT composites.

\section{Quasi static indentation process}

Elastic modulus and hardness results obtained for various MWCNT compositions in ABS/MWCNT composites using the nano-indentation are given in Table-1. Results indicates consistent enhancement in both modulus and hardness with increase in MWCNT composition. For the highest MWCNT composition of $10 \mathrm{wt} \%$ in ABS, an increase in modulus and hardness of $61 \%$ and $49 \%$ respectively, observed in comparison to pure ABS. Based on the previous literature reported on enhancement of mechanical properties [19] of polymer composites by embedding minor MWCNT compositions, it has been shown that for ABS polymer also there is significant enhancement in mechanical properties like tensile properties for similar compositions [20].

Table 1. Elastic Modulus and Hardness for various ABS/MWCNT compositions under quasi-static loading.

\begin{tabular}{ccccc}
\hline Sample & $\begin{array}{c}\text { Elastic Modulus } \\
\text { E(GPa) }\end{array}$ & $\begin{array}{c}\text { E(GPa) error } \\
\text { deviation }(+/-)\end{array}$ & $\begin{array}{c}\text { Hardness } \\
\text { H(GPa })\end{array}$ & $\begin{array}{c}\text { H(GPa) error } \\
\text { deviation }(+/-)\end{array}$ \\
\hline Pure ABS & 2.061 & 0.265 & 0.150 & 0.044 \\
MWCNT 3\% & 2.359 & 0.212 & 0.197 & 0.032 \\
MWCNT 5 \% & 3.021 & 0.158 & 0.210 & 0.017 \\
MWCNT 10\% & 3.311 & 0.268 & 0.223 & 0.025 \\
\hline
\end{tabular}

\section{Dynamic Mechanical Analysis (DMA) Indentation Process}

The visco-elastic behaviour of the polymer composites is investigated in dynamic condition by using DMA. As the visco-elastic material properties change with loading frequency, the ABS/MWCNT composite properties were investigated under variable loading frequencies upto $200 \mathrm{~Hz}$. Variation of storage modulus with frequency for $10 \mathrm{wt} \%$, $5 \mathrm{wt} \% \mathrm{ABS} / \mathrm{MWCNT}$ composite and pure ABS are shown in Figure-6. The variation in storage modulus helps in assessing the mechanical properties of the material at different loading frequencies. With the increase in MWCNT composition in ABS, a significant enhancement in storage modulus was observed for the complete frequency range. Though, the enhancement indicated variation in the modulus with frequency but the increase in modulus was found to be at least $20 \%$ higher for each specific loading frequency for ABS/MWCNT composite in comparison to pure ABS. The storage modulus behaviour of these composites appears to have a uniform pattern with increase in frequency and reached a maximum value for a specific loading frequency. It was observed that for $10 \mathrm{wt} \%$ ABS/MWCNT composite, the highest storage modulus was 3.95 $\mathrm{GPa}$ at $85 \mathrm{~Hz}$. For $5 \mathrm{wt} \%$ ABS/MWCNT the maximum value $(3.25 \mathrm{GPa})$ reached at 130 $\mathrm{Hz}$ and but for pure ABS specimen the maximum value is $2.3 \mathrm{GPa}$ at about $160 \mathrm{~Hz}$. This pattern indicates that for low to medium frequency range applications of about $100 \mathrm{~Hz}$, $10 \mathrm{wt} \% \mathrm{ABS} / \mathrm{MWCNT}$ provide maximum strength. The storage modulus for $10 \mathrm{wt} \%$ 
ABS/MWCNT composite always remains higher by more than $50 \%$ for the complete frequency range and the maxima is achieved at a much lower loading frequency than pure ABS. The frequency dependent properties promote the prospects of ABS/MWCNT for different types of dynamic loading applications.

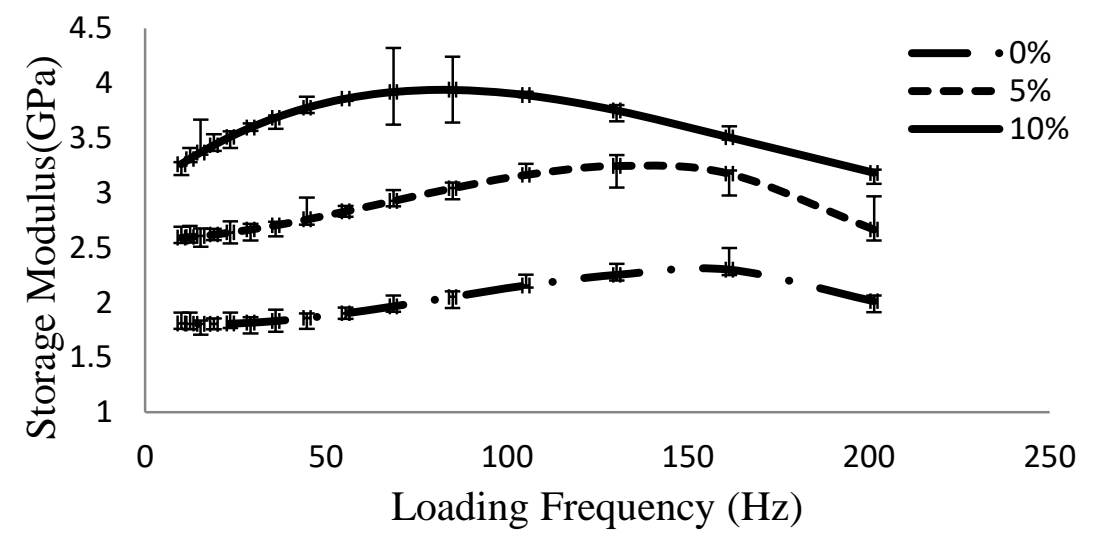

Figure 6. Storage Modulus variation with loading frequency for various ABS/MWCNT compositions.

These results indicated that under dynamic loading conditions, ABS/MWCNT composites exhibited enhanced mechanical properties in comparison to the pure ABS, therefore presence of MWCNTs widens the scope of ABS/MWCNTs composites for various types of mechanical engineering applications. Once the specimens were subjected to variable loading frequencies, then the measure of storage modulus for $5 \mathrm{wt} \%$ and $10 \mathrm{wt} \%$ ABS/MWCNT composite indicated significant enhancement for a frequency range up to $100 \mathrm{~Hz}$. The increase in storage modulus with higher MWCNT composition is primarily due to the stiffening effect [21] of nanotubes under high frequency loading. After attaining a maximum value, certain rearrangements between polymer molecules and nanotubes take place leading to internal friction among them. Hence, energy losses [22] take place due to which lowering of modulus is observed beyond the critical frequency point. Moreover, enhanced modulus of these composites at low frequency response is indicative of 'pseudo-solid-like' behaviour which has been observed for conventionally filled polymers having stronger interactions between filler and polymer and leads to yielding phenomena in the composite [23]. Even under quasi static loading conditions a consistent improvement in both modulus and hardness has been observed with increase in MWCNT composition. Considering, that if any component needs to be designing for applications wherein external loading undergoes larger variations, the dynamic mechanical behaviour plays a significant role. As observed, that in the case of ABS based composite materials presence of MWCNTs fillers enhances the utility of such materials for different range of frequencies. Hence, a single kind of polymer nanocomposites may be used for a wide variety of applications just be altering the presence of MWCNTs in them. Such studies if carried our further at rapidly changing loading frequencies can lead to major improvements in engineering components.

Table 1 and Figure 6 show that, hardness and modulus for ABS/MWCNT composites improves significantly for both static and dynamic loading in comparison with pure ABS specimen possibly due to better load transfer [24] properties and adhesion [25, 26] of MWCNTs with ABS. We also suggest that, presence of MWCNTs prevents any deterioration due to retarded chain mobility [27, 28] and immobilisation [29] of polymer 
leading to enhanced mechanical properties of the composite. In the case of ABS/MWCNTs nanocomposites tensile strength evaluation results, it has been reported [30] that significant enhancement(29\%) was observed for nearly 3wt\% MWCNT composition in ABS in comparison to pure ABS. Similarly, Saleh et al. [20] have reported that due to good dispersion of the nanofiller and physical interfacial adhesion between the CNT and ABS, tensile properties enhanced by nearly $72 \%$ for $10 \mathrm{wt} \% \mathrm{MWCNT} / \mathrm{ABS}$ composites in comparison to pure ABS specimen.

\section{CONCLUSIONS}

Static and dynamic mechanical characterisation tests using nano-indention were performed on various compositions $(3,5,10 \mathrm{wt} \%)$ of MWCNTs in ABS/MWCNT composites. It was observed that there was a consistent enhancement in the static properties of the composites with increase in MWCNT content. For the $10 \mathrm{wt} \%$ MWCNT composition, it was observed that the enhancement in hardness and elastic modulus was $49 \%$ and $61 \%$ respectively in comparison to pure ABS, which makes these composites suitable for various types of engineering applications where static load resistance is needed. Results published related to tensile properties of these composite materials indicated nearly $70 \%$ enhancement for similar compositions thereby suggesting ABS/MWCNT based nano-composite materials as a promising stronger material for the future. The DMA tests were performed for a high frequency range up to $200 \mathrm{~Hz}$ and the results indicated that the increase in storage modulus of $10 \mathrm{wt} \%$ MWCNT composition was consistently higher than $50 \%$ in comparison to pure ABS samples for the complete frequency range, thereby enabling this material to be used for a wide variety of engineering applications just by altering the presence of MWCNTs. Better load transfer properties of MWCNTs and its adhesion with ABS matrix are the suggested reasons for the improvement in mechanical properties of these composite materials. Future experiments related to high impact, strain rate and frequency loadings for these composite materials can be performed which will enable their usage for developing high energy and pressure absorbing materials also. Simulation studies using specific mathematical models can also be developed to validate experimental data.

Therefore, this work highlights the significance of minor compositions of MWCNTs in ABS composites for quasi-static loading and low to medium range loading frequency applications. ABS is widely used in applications where impact and varying load resistance is required. The results of these experiments indicate that presence of MWCNTs is going to further enhance these properties of ABS composite materials. Practical applications related to automotive body and machine parts, where loading varies from small to medium frequencies, specific material composites using MWCNTs as filler materials can be preferred due to the light weight and higher strength of MWCNTs. To obtain a wider spectrum of mechanical properties like damping behaviour, energy absorption etc. more experiments at different loading frequencies with other MWCNT compositions can be conducted.

\section{ACKNOWLEDGEMENTS}

The authors are very grateful to Directors of the affiliated institutions for technical support related to these experiments. 


\section{REFERENCES}

[1] Li J, Cai C. The carbon fiber surface treatment and addition of PA6 on tensile properties of ABS composites. Current Applied Physics. 2011;11:50-4.

[2] Spitalsky Z, Tasis D, Papagelis K, Galiotis C. Carbon nanotube-polymer composites: chemistry, processing, mechanical and electrical properties. Progress in Polymer Science. 2010;35:357-401.

[3] Meincke O, Kaempfer D, Weickmann H, Friedrich C, Vathauer M, Warth H. Mechanical properties and electrical conductivity of carbon-nanotube filled polyamide- 6 and its blends with acrylonitrile/butadiene/styrene. Polymer. 2004;45:739-48.

[4] Difallah BB, Kharrat M, Dammak M, Monteil G. Mechanical and tribological response of ABS polymer matrix filled with graphite powder. Materials \& Design. 2012;34:782-7.

[5] Olek M, Kempa K, Jurga S, Giersig M. Nanomechanical properties of silicacoated multiwall carbon nanotubes poly (methyl methacrylate) composites. Langmuir. 2005;21:3146-52.

[6] Rahmanian S, Suraya A, Othman R, Zahari R, Zainudin E. Growth of carbon nanotubes on silica microparticles and their effects on mechanical properties of polypropylene nanocomposites. Materials \& Design. 2015;69:181-9.

[7] Gupta TK, Singh BP, Dhakate SR, Singh VN, Mathur RB. Improved nanoindentation and microwave shielding properties of modified MWCNT reinforced polyurethane composites. Journal of Materials Chemistry A. 2013;1:9138-49.

[8] Jindal P, Pande S, Sharma P, Mangla V, Chaudhury A, Patel D, et al. High strain rate behavior of multi-walled carbon nanotubes-polycarbonate composites. Composites Part B: Engineering. 2013;45:417-22.

[9] Jindal P, Goyal M, Kumar N. Modeling Composites of Multi-Walled Carbon Nanotubes in Polycarbonate. International Journal for Computational Methods in Engineering Science and Mechanics. 2013;14:542-51.

[10] Ravisankar B, Chand VT. Influence of nanoparticle volume fraction, particle size and temperature on thermal conductivity and viscosity of nanofluids-A review. International Journal of Automotive and Mechanical Engineering. 2013;8:131638.

[11] Hadzreel MAM, Aisha ISR. Effect of reinforcement alignment on the properties of polymer matrix composite. Journal of Mechanical Engineering and Sciences.2013; 4:548-54.

[12] Salleh Z, Yusop M, Rosdi M. Mechanical properties of activated carbon coir fibers reinforced with epoxy resin. Journal of Mechanical Engineering and Sciences.Journal of Mechanical engineering and Sciences. 2013;5:631-8.

[13] Pande S, Mathur R, Singh B, Dhami T. Synthesis and characterization of multiwalled carbon nanotubes-polymethyl methacrylate composites prepared by in situ polymerization method. Polymer Composites. 2009;30:1312-7.

[14] Mathur R, Chatterjee S, Singh B. Growth of carbon nanotubes on carbon fibre substrates to produce hybrid/phenolic composites with improved mechanical properties. Composite Science and Technology. 2008;68:1608-15.

[15] Babal AS, Gupta R, Singh BP, Singh VN, Dhakate SR, Mathur RB. Mechanical and electrical properties of high performance MWCNT/polycarbonate composites 
prepared by an industrial viable twin screw extruder with back flow channel. RSC Advances. 2014;4:64649-58.

[16] Jindal P, Goyal M, Kumar, N. Mechanical characterization of multiwalled carbon nanotubes-polycarbonate composites. Materials \& Design. 2014;54:864-8.

[17] Oliver WC, Pharr GM. Measurement of hardness and elastic modulus by instrumented indentation: Advances in understanding and refinements to methodology. Journal of Materials Research. 2011;19:3-20.

[18] Majid MA, Daud R, Afendi M, Amin N, Cheng E, Gibson A, et al. Stress-Strain Response Modelling Of Glass Fibre Reinforced Epoxy Composite Pipes under Multiaxial Loadings. Journal of Mechanical Engineering and Sciences. 2014;1:916-28.

[19] Al-Saleh MH, Al-Saidi, B. A., \& Al-Zoubi, R. M. Experimental and Theoretical Analysis of the Mechanical and Thermal Properties of Carbon Nanotube/Acrylonitrile-Styrene-Butadiene Nanocomposites. Polymer. 2016;89:12-7.

[20] Valentini L, Biagiotti J, Kenny J, Santucci S. Morphological characterization of single-walled carbon nanotubes-PP composites. Composite Science and Technology. 2003;63:1149-53.

[21] Li X, Gao H, Scrivens WA, Fei D, Xu X, Sutton MA, et al. Nanomechanical characterization of single-walled carbon nanotube reinforced epoxy composites. Nanotechnology. 2004;15:1416.

[22] McNally T, Pötschke P, Halley P, Murphy M, Martin D, Bell SE, et al. Polyethylene multiwalled carbon nanotube composites. Polymer. 2005;46:822232.

[23] Vivekchand S, Ramamurty U, Rao C. Mechanical properties of inorganic nanowire reinforced polymer-matrix composites. Nanotechnology. 2006; 17:S344.

[24] Jindal P, Goyal M, Kumar N. Dynamic impact absorption behaviour of glass coated with carbon nanotubes. Journal of Surface Engineered Materials and Advanced Technology. 2013;3:257.

[25] Kim KH, Jo WH. Improvement of tensile properties of poly (methyl methacrylate) by dispersing multi-walled carbon nanotubes functionalized with poly (3hexylthiophene)-graft-poly (methyl methacrylate). Composite Science and Technology. 2008;68:2120-4.

[26] Maiti S, Suin S, Shrivastava NK, Khatua B. Low percolation threshold in polycarbonate/multiwalled carbon nanotubes nanocomposites through melt blending with poly (butylene terephthalate). Journal of Applied Polymer Science. 2013;130:543-53.

[27] Wu TM, Chen EC, Lin YW, Chiang MF, Chang GY. Preparation and characterization of melt-processed polycarbonate/multiwalled carbon nanotube composites. Polymer Engineering \& Science. 2008;48:1369-75.

[28] Eitan A, Fisher F, Andrews R, Brinson L, Schadler L. Reinforcement mechanisms in MWCNT-filled polycarbonate. Composite Science and Technology. 2006;66:1162-73.

[29] Jyoti J, Basu S, Singh BP, Dhakate S. Superior mechanical and electrical properties of multiwall carbon nanotube reinforced acrylonitrile butadiene styrene high performance composites. Composites Part B: Engineering. 2015;83:58-65. 